\title{
OROIASIOHO
}

\section{KARAKTERISTIK TERMAL HIDRODINAMIK UNTUK ALIRAN LAMINAR DAN TURBULEN DI DALAM PIPA DENGAN BERBAGAI BENTUK SISIPAN PLAT BERGALUR}

\author{
*Syaiful, Faza Dzulhimam \\ Jurusan Teknik Mesin, Fakultas Teknik, Universitas Diponegoro \\ Jl. Prof. Sudarto SH, Tembalang, Semarang \\ *E-mail: syaiful.undip2011@gmail.com
}

\begin{abstract}
The purpose of this study is to investigate the thermal and hydrodynamic characteristics of air flowing in tubes with various inserts of grooved plate. Inserts of grooved plate with a variety of attack angles $\left(\alpha=0^{\circ}, 45^{\circ}\right.$ and $\left.90^{\circ}\right)$ has been studied in laminar and turbulent flow. Plate inserts are installed inside the tube intended to improve the heat transfer due to the mixing of the fluid. Numerical simulation of three-dimensional flow set as a model in the direction of fluid flow. The working fluid in the tube is cold, whereas hot wall temperature is kept constant. The results showed that the grooved plate inserts increases the heat transfer in the tube. For laminar flow, the highest heat transfer enhancement is obtained at the grooved plate inserts $\alpha=45^{\circ}$ i.e. from 4.46 to $20.34 \%$ with an increase in friction factor of 172.19 to $204.36 \%$. As for the turbulent flow, the highest heat transfer improvement is found in a grooved plate inserts with $\alpha=45^{\circ}$ i.e. from 38.67 to $56.1 \%$ with an increase in friction factor of 183.5 to $262.29 \%$.
\end{abstract}

Keyword: Diesel engines, NOx emissions, Ammonia-SCR system, Ammonia injector location, Mixing index

\section{PENDAHULUAN}

Heat exchanger (penukar kalor) secara luas digunakan di berbagai bidang seperti pembangkit listrik, industri kimia, metalurgi, produksi baja, refrigerasi, AC dan lain-lain. Variabel paling signifikan yang dapat mengurangi ukuran dan biaya penukar panas adalah koefisien perpindahan panas dan penurunan tekanan (pressure drop). Peningkatan koefisien perpindahan panas sering menyebabkan peningkatan resistensi aliran, sehingga mengurangi efisiensi energy [1].

Peningkatan efisiensi merupakan masalah teknik yang dominan dalam suatu proses industri. Pada penelitian sebelumnya, kajian eksperimental Yu-Wei Chiu dan Jiin-Yuh Jang meneliti tentang vortex generator, dimana dalam penelitian ini sebuah plat dengan berbagai tipe (plat, plat berlubang dan plat yang dipuntir) disisipkan dalam pipa-pipa pada penukar kalor jenis shell and tube [2]. Dari penelitian ini didapatkan pengaruh dari berbagai sisipan plat terhadap bilangan Nusselt dan kerugian tekanan (pressure drop).

Bhuiya dkk. mempelajari karakteristik termal penukar kalor degan tiga sisipan plat terpuntir[3]. Penggunaan tiga sisipan plat terpuntir meningkatkan perpindahan panas lebih tinggi dibandingkan dengan sisipan datar. Bhuiya dkk. meneliti performa penukar kalor dengan sisipan plat terpuntir ganda [4]. Mereka memperoleh bahwa efisiensi peningkatan panas dan faktor gesekan meningkat dengan menurunnya rasio puntiran. Azmi dkk. melakukan eksperiment dan perhitungan numerik untuk aliran nanofluid di dalam pipa dengan sisipan plat terpuntir [5]. Peningkatan koefisien perpindahan panas di atas $90 \%$ diperoleh dari penelitian mereka. Akan tetapi peningkatan perpindahan panas ini juga diikuti oleh kenaikan yang besar dari pressure drop sampai $160 \%$. Karakteristik perpindahan panas dan gesekan di dalam pipa dengan sisipan plat terpuntir yang baru diperkenalkan oleh Changzhong Man dkk. melalui kaji eksperimental [6]. Mereka meneliti efek sisipan plat terpuntir yang baru dengan beberapa perbedaan panjang plat terhadap perpindahan panas dan gesekan.

Vortex generator merupakan sebuah terobosan untuk meningkatkan performa heat exchanger dengan menimbulkan swirling motion dan memicu terjadinya pencampuran fluida. Pencampuran fluida ini meningkatkan koefisien perpindahan panas konveksi dari dinding pipa ke fluida atau sebaliknya dalam heat exchanger. Pressure drop merupakan batasan dari jenis heat exchanger yang akan digunakan karena akan memicu pengotoran di dalam heat exchanger. Oleh karena itu dibutuhkan simulasi numerik untuk mempermudah penentuan tipe vortex generator yang optimum baik dari segi koefisien konveksinya maupun meminimalisasi pengotoran akibat penurunan tekanan. Metode numerik merupakan solusi alternatif dalam analisis dinamika aliran fluida (Computational Fluid Dynamic, CFD) dalam heat exchanger dengan tambahan sisipan oleh karena biaya yang relatif mahal dan waktu yang cukup lama dalam kajian eksperimental. Metode numerik dapat memprediksi sesuatu dengan lebih cepat dan mudah. Di samping itu metode numerik juga dapat mengatasi kendala geometri yang rumit dan syarat-syarat batas yang merupakan penghambat metode analitis. Simulasi numerik digunakan untuk mengetahui karakteristik termalhi drodinamik dari pipa khususnya karakteristik performa dengan sisipan plat yang sulit dilihat langsung melalui eksperimen tanpa menggunakan alat-alat canggih seperti kamera thermal. 
Pada penelitian ini, sebuah pemodelan aliran pada tube dengan berbagai bentuk sisipan plat bergalur dibuat. Tujuan yang ingin dicapai dalam penelitian ini adalah mengetahui efek sisipan plat bergalur terhadap peningkatan bilangan Nusselt rata-rata dan pressure drop aliran.

\section{METODOLOGI}

Model yang dikaji dalam masalah ini adalah penukar kalor jenis shell and tube dengan dan tanpa sisipan. Fokus penelitian ini yaitu melihat fenomena yang terjadi dalam aliran, mengetahui pengaruh dari sisipan plat terhadap bilangan Nusselt dan friction factor. Dalam simulasi tidak melibatkan reaksi kimia yang terjadi. Fluida yang masuk pada pipa merupakan fluida dingin dan tube wall merupakan dinding dinding panas. Kecepatan divariasikan mulai dari $0,1 \mathrm{~m} / \mathrm{s}-0,42 \mathrm{~m} / \mathrm{s}$ untuk aliran laminar dan $4,52 \mathrm{~m} / \mathrm{s}-7,65 \mathrm{~m} / \mathrm{s}$ untuk aliran turbulen.

Analisa aliran dilakukan pada keadaan steady dengan aliran laminar $\operatorname{Re}<2300$ dan untuk aliran turbulen, $\operatorname{Re}>$ 10.000. Fluida di dalam pipa diasumsikan incompressible dengan dinding pipa diasumsikan pada keadaan tanpa slip. Adapun model geometri plat sisipan yang menjadi objek penelitian ini dapat ditunjukkan pada Gambar 1. Penelitian ini dilakukan di Lab. Termofluida Jurusan Teknik Mesin Universitas Diponegoro. Variabel yang diubah-ubah (independence variable) adalah kecepatan aliran fluida untuk aliran laminar dan turbulen. Beberapa parameter yang diamati dalam penelitian ini diantaranya bilangan Nusselt di dalam pipa untuk berbagai variasi kecepatan fluida, koefisien gesekan fluida di dalam pipa. Validasi dilakukan dengan membandingkan beberapa hasil penelitian dengan teori yang sudah ada.

Berdasarkan geometri yang diperlihatkan pada Gambar 1, domain komputasi dari simulasi ditentukan hanya setengah dari volume oleh karena bentuk yang simetris seperti yang diperlihatkan pada Gambar 2. Hal ini dilakukan untuk mengurangi jumlah grid yang dibangun guna mengurangi waktu simulasi.

Daerah upstream extended dimana inlet terdapat merupakan volume grid perpanjangan untuk mendapatkan distribusi kecepatan yang fully developed di sisi inlet sebenarnya. Volume grid ini dihitung dengan menggunakan panjang daerah masuk untuk aliran laminer dan turbulen yang dapat dirumuskan sebagai berikut:
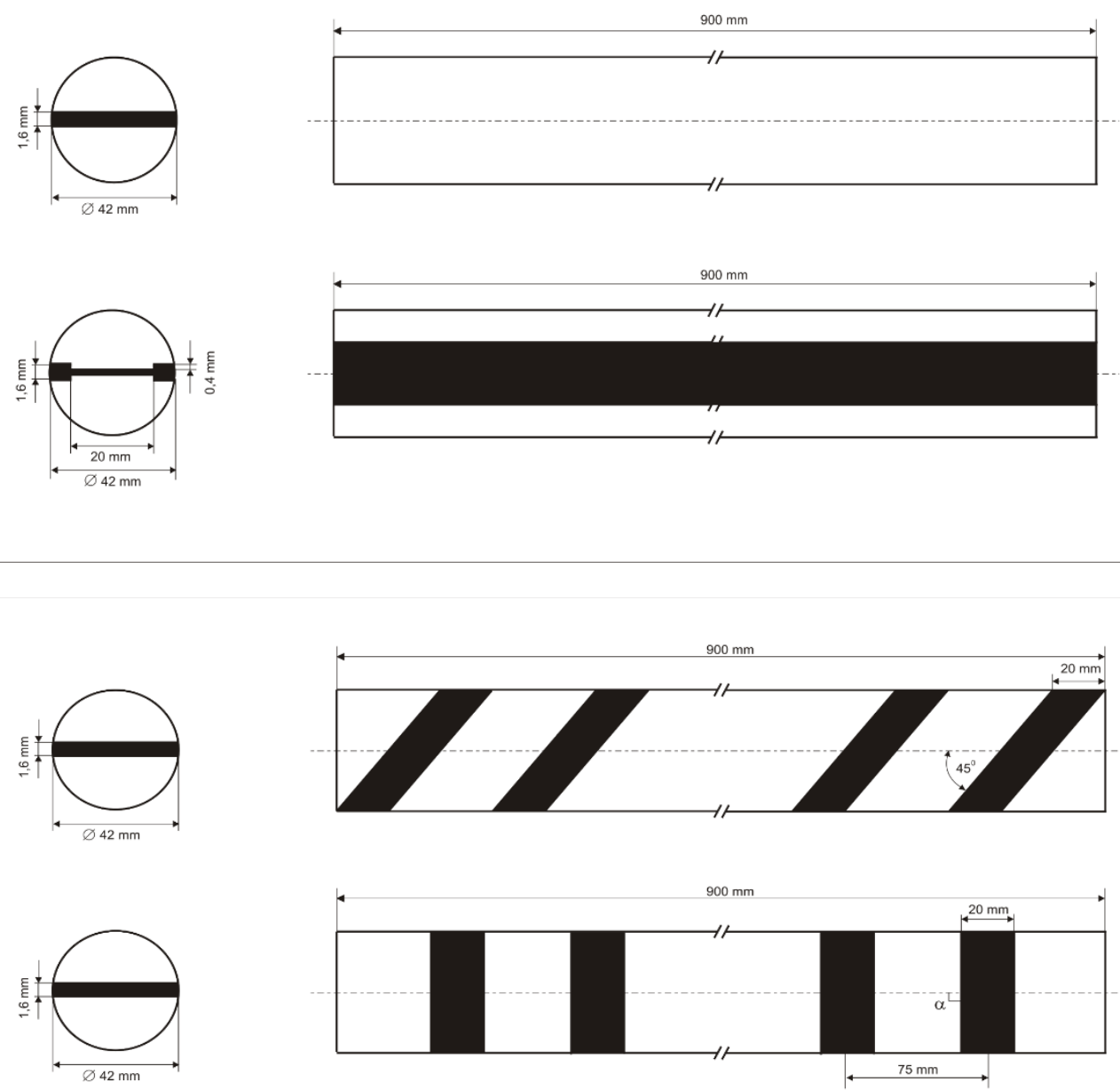

Gambar 1. Berbagai jenis sisipan plat bergalur 


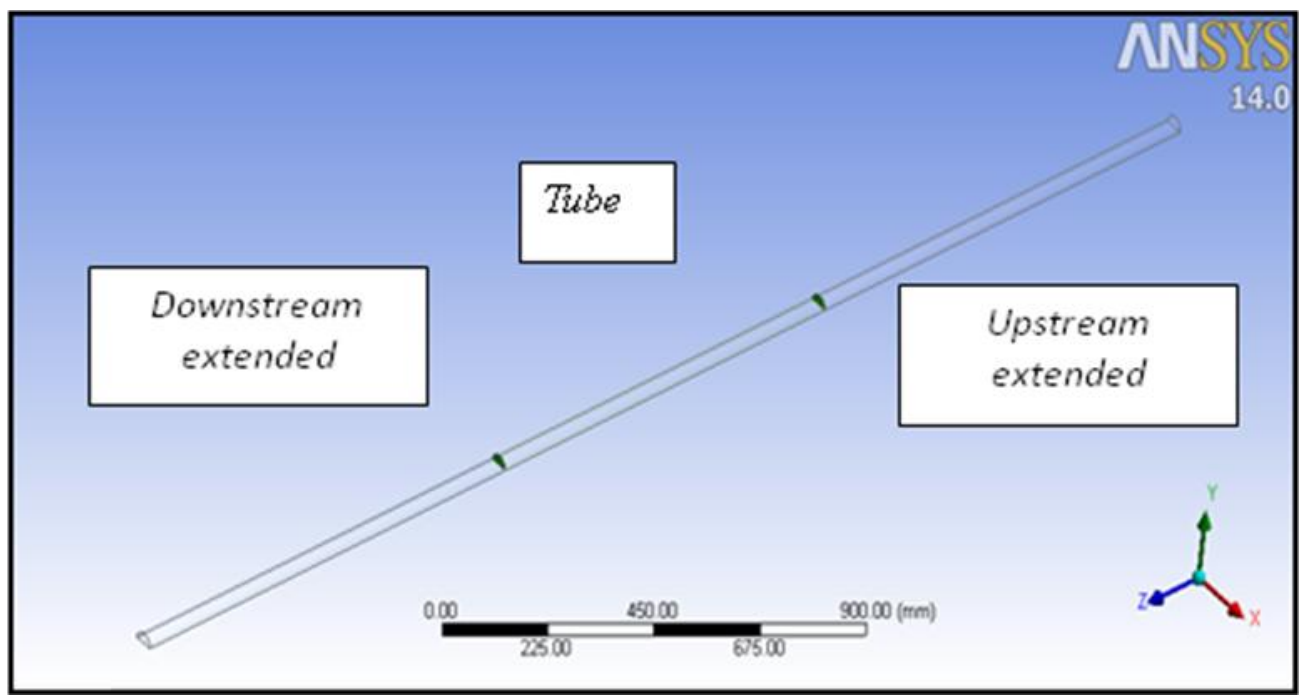

Gambar 2. Geometri control volume dari domain komputasi

$l_{e}=0,06 R_{e} D_{h} \quad$ untuk aliran laminer

$l_{e}=4,4 R_{e}^{1 / 6} D_{\hbar} \quad$ untuk aliran turbulen

Yang kedua adalah daerah pipa dimana objek yang diamati terletak di dalamnya. Di daerah ini plat dengan sisipan bergalur untuk berbagai sudut galur diletakkan. Dalam simulasi ini dua sudut galur yang disimulasikan yaitu $45^{\circ}$ dan $90^{\circ}$ seperti yang ditunjukkan pada Gambar 1.

Dan yang ketiga adalah daerah downstream extended (perpanjangan daerah belakang). Perpanjangan volume grid di daerah belakang dihitung dengan cara yang sama seperti menentukan upstream extended. Perpanjangan daerah di bagian belakang ini penting di dalam perhitungan numerik karena daerah belakang ini harus jauh dari gangguangangguan aliran untuk mendapatkan hasil yang valid.

Penggenerasian mesh dilakukan dengan menggunakan metode sweep dengan jenis mesh hexahedral seperti yang diperlihatkan pada Gambar 3. Ukuran element size yang di set pada daerah yang tanpa sisipan yaitu $10^{-3} \mathrm{~m}$ sedangkan pada daerah yang terpasang sisipan, meshing dilakukan dengan element size antara $10^{-1}-10^{-3} \mathrm{~m}$. Di daerah dekat dinding (wall) dan dekat sisipan, meshing dirapatkan dengan cara inflation yang terdiri dari 5 layer (lapisan).

Fluida yang digunakan dalam simulasi ini yaitu udara dengan temperatur masuk $293 \mathrm{~K}$ dan bilangan Reynold berkisar antara $300-1.200$ untuk aliran laminer dan $13.000-22.000$ untuk aliran turbulen. Temperatur dinding tube dipertahankan konstan pada $350 \mathrm{~K}$. Simulasi dilakukan pada 3 dimensi dengan adanya perpindahan panas. Kesetimbangan energi diberlakukan dalam perhitungan oleh karena adanya perpindahan panas. Standard $k-\varepsilon$ model digunakan untuk memodelkan aliran turbulen di dalam pipa.

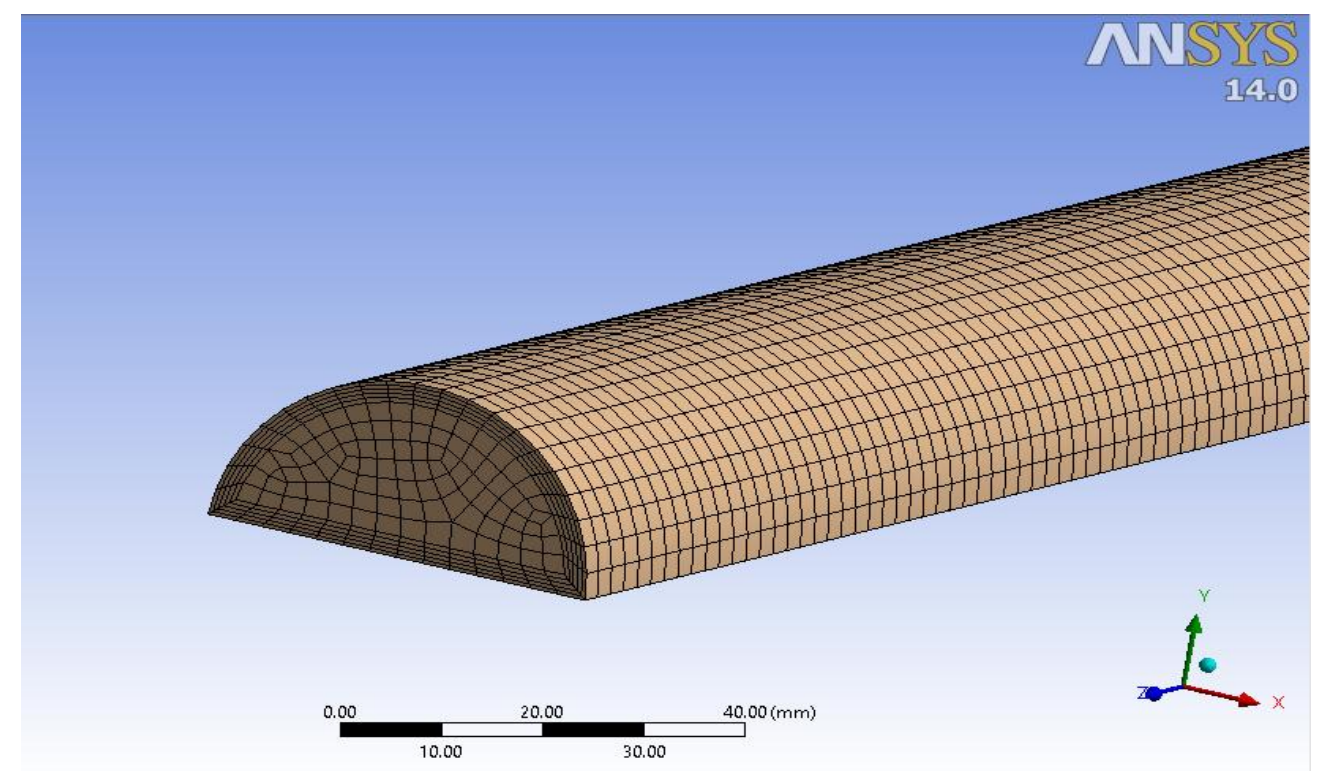

Gambar 3. Mesh hexahedral untuk pipa dengan dan tanpa sirip bergalur. 
Kondisi batas di sisi masuk (inlet) pada daerah extended upstream ditentukan dengan menetapkan kecepatan pada sisi masuk seragam dalam satu arah aliran dengan temperatur $293 \mathrm{~K}$. Intensitas turbulen ditetapkan 4,6\% pada kondisi batas inlet dengan diameter hidraulik 0,042 m. Intensitas turbulen dan diameter hidraulik ini digunakan untuk menghitung energi kinetik turbulen dan laju disipasi pada kondisi batas inlet. Intensitas turbulen ini ditentukan pada Persamaan (3).

$$
I=0,16 R_{e}^{-0,8}
$$

Kondisi batas dinding (wall boundary condition) ditentukan dengan menetapkan no slip condition yang berarti semua vector kecepatan nol di permukaan dinding. Untuk daerah sisi bawah dari tube didefinisikan simetri yang merupakan pencerminan berkelanjutan searah arah simetrinya. Dengan mendefinisikan menjadi simetris, maka keadaan aliran yang terjadi disebelahnya setara dan dipengaruhi oleh aliran simetrisnya. Pendefinisian sebagai simetris juga sangat bermanfaat untuk mereduksi besarnya domain komputasi yang harus dibuat dan optimalisasi jumlah mesh. Hal ini berguna untuk menurunkan konsumsi waktu simulasi.

Pada kondisi batas outlet, tekanan pada sisi ini ditentukan sama dengan tekanan atmosfir. Lokasi kondisi batas outlet di tentukan jauh dari gangguan-gangguan oleh karena geometri saluran. Pada kondisi batas ini, semua gradien variabel sama dengan nol pada arah kecepatan aliran kecuali tekanan.

Perhitungan pada pemodelan ini dilakukan pada keadaan steady. Viscous model aliran dimodelkan sebagai aliran laminer dan aliran turbulen. Semi-Implicit Method for Pressure- Linked Equations (SIMPLE) digunakan untuk memperhitungkan kecepatan dan tekanan. Diskritisasi persamaan momentum, kinetik energi, laju disipasi dan energi ditetapkan dengan menggunakan second upwind differencing scheme.

Nilai dari under relaxation factor diubah untuk mendapatkan kestabilan dari perhitungan numerik yang dipantau melalui grafik nilai residual. Nilai default dari under relaxation factor untuk momentum adalah 0,7. Untuk mendapatkan nilai perhitungan yang benar dari simulasi, eror residual untuk momentum, energi kineti dan laju disipasi ditentukan maksimum 10-6. Sedangkan energi ditentukan maksimum 10-8. Selain itu, penyelesaian model matemetik membutuhkan nilai awal sebagai nilai tebakan. Nilai awal ini ditentukan berdasarkan data masukan di sisi inlet.

Bilangan Nusselt dihitung dengan menggunakan Persamaan (4).

$\overline{N u}=\frac{h d_{i}}{k}$

dimana $\overline{\mathbb{N} u}$ adalah bilangan Nusselt rata-rata, $\mathrm{h}$ adalah koefisien perpindahan panas konveksi, $\mathrm{d}_{\mathrm{i}}$ adalah diameter dan $\mathrm{k}$ adalah konduktifitas termal dari fluida. Koefisien konveksi, h, ditentukan dengan menggunakan Persamaan (5).

$h=\frac{q}{A_{s} \Delta T_{l m}}$

dimana $\mathrm{q}$ adalah laju panas, $\mathrm{A}_{\mathrm{s}}$ adalah luas permukaan perpindahan panas dan $\Delta \mathrm{T}_{\mathrm{Im}}$ adalah beda temperatur rata-rata logaritmik. Dengan menggunakan prinsip kekekalan energi antara fluida panas yang masuk dan keluar dengan laju perpindahan panas, laju panas dapat dihitung menggunakan Persamaan (6).

$q=\dot{m} c_{\mathrm{p}}\left(T_{\text {out }}-T_{\text {in }}\right)$

dimana $\dot{m}$ adalah laju masa fluida masuk pipa, $c_{p}$ adalah panas jenis pada tekanan konstan dan $T_{\text {in }}$ serta $T_{\text {out }}$ berturutturut adalah temperatur fluida masuk dan keluar. Laju masa fluida masuk pipa ditentukan dengan menggunakan Persamaan (7).

$\dot{m}=\rho v A_{c}$

dimana $v$ adalah kecepatan fluida masuk pipa dan $\mathrm{A}_{\mathrm{c}}$ adalah luas penampang pipa. Sedangkan $\Delta \mathrm{T}_{\mathrm{lm}}$ ditentukan menggunakan Persamaan (8).

$$
\Delta T_{\mathrm{lm}}=\frac{\Delta T_{0}-\Delta T_{i}}{\ln \frac{\Delta T_{0}}{\Delta T_{i}}}
$$

Faktor gesekan ditentukan dengan menggunakan Persamaan (9).

$f=\frac{\Delta p}{\rho v^{2}} \frac{d_{i}}{2 I}$

dimana $\Delta \mathrm{P}$ adalah pressure drop, $v$ adalah kecepatan fluida, $\mathrm{d}_{\mathrm{i}}$ adalah diameter inlet dan $l$ adalah panjang pipa. 


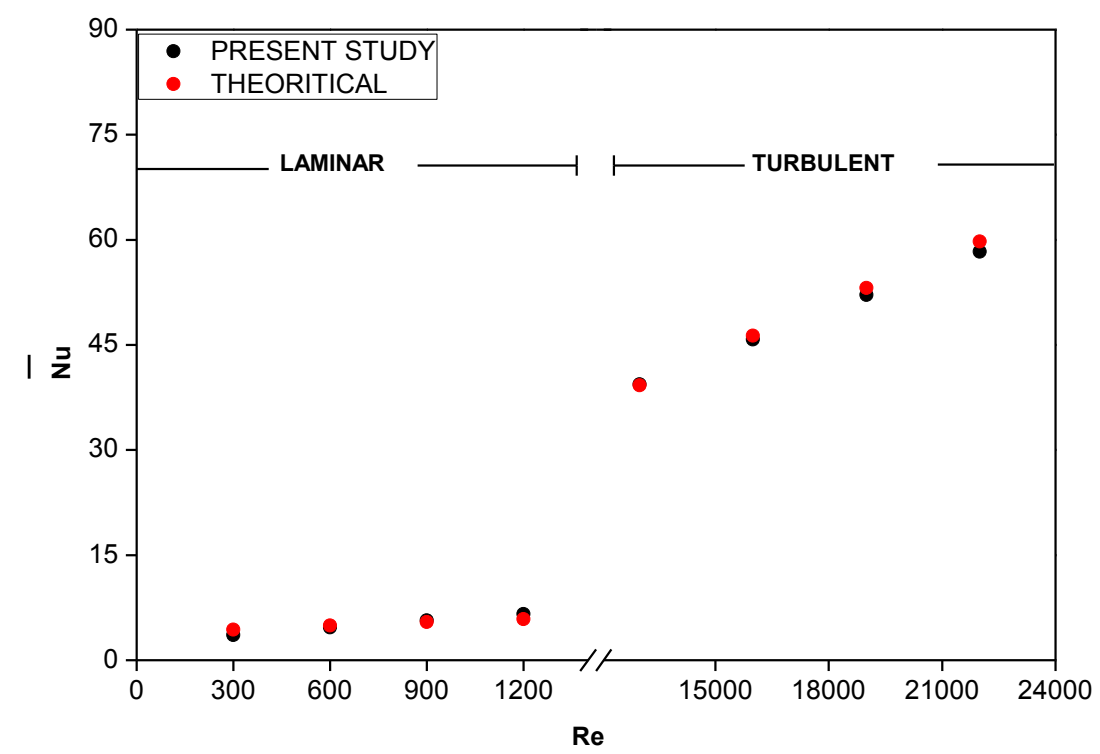

Gambar 4. Perbandingan antara bilangan Nusselt hasil simulasi dengan hasil perhitungan teoritis

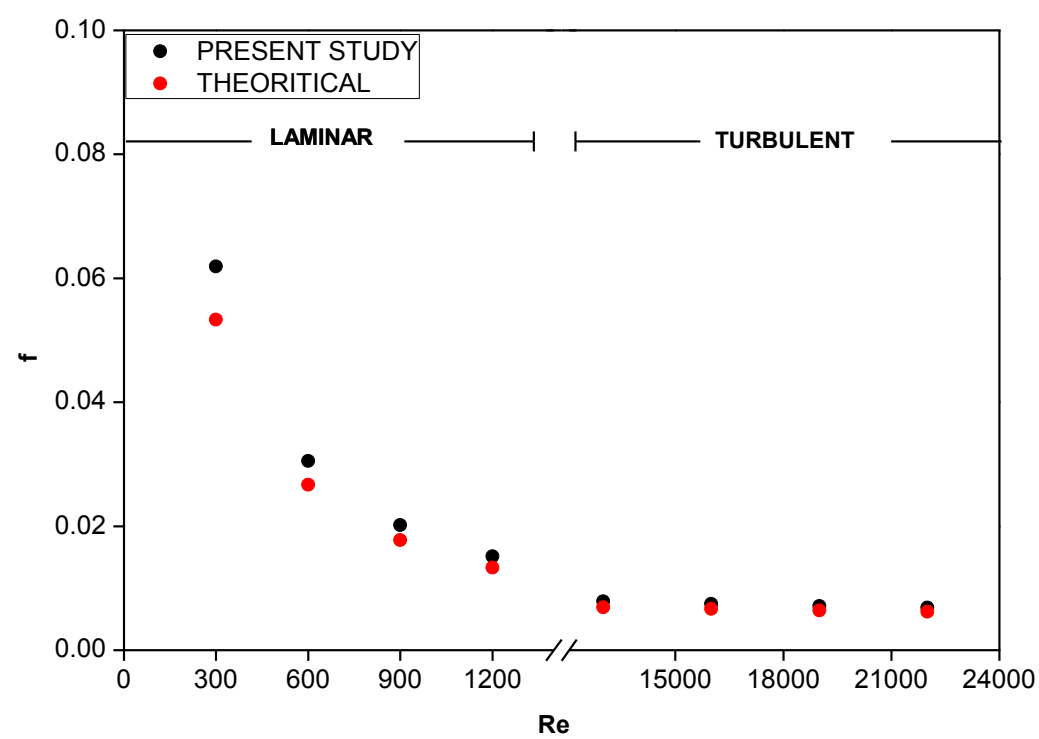

Gambar 5. Perbandingan antara faktor gesekan hasil simulasi dengan hasil perhitungan teoritis

Untuk mendapatkan hasil simulasi yang benar, validasi dilakukan dengan membandingkan hasil yang diperoleh dari simulasi dengan hasil dari perhitungan dengan menggunakan rumus teori yang sudah ada. Parameter hasil perhitungan yang diperoleh dari simulasi adalah bilangan Nusselt dan faktor gesekan seperti yang ditunjukkan pada Gambar 4 dan 5. Dari kedua gambar validasi tersebut dapat disimpulkan bahwa perbedaan antara hasil perhitungan simulasi dan hasil perhitungan dari teori sangat kecil baik untuk kasus laminer dan turbulen.

\section{HASIL DAN PEMBAHASAN}

Gambar 6 menunjukkan grafik perbandingan rata - rata bilangan Nusselt antara plain tube dan tube dengan berbagai variasi sisipan. Grafik ini berisi tentang pengaruh variasi sisipan terhadap rata - rata bilangan Nusselt. Sumbu x menunjukkan bilangan Reynolds sedangkan sumbu y menunjukkan rata - rata bilangan Nusselt. Simbol kotak hitam menunjukkan tube tanpa sisipan, bentuk lingkaran biru menunjukkan tube yang dipasang sisipan tanpa galur, bentuk segilima hijau menunjukkan tube yang dipasang sisipan dengan galur $\alpha=0^{0}$, bentuk diamond merah menunjukkan tube yang dipasang sisipan dengan galur $\alpha=45^{\circ}$, dan bentuk segitiga coklat menunjukkan tube yang dipasang sisipan dengan galur $\alpha=90^{\circ}$. Dari grafik ini dapat ditunjukkan bahwa kecenderungan rata - rata bilangan Nusselt meningkat terhadap bilangan Reynolds. Semakin besar bilangan Reynolds, maka semakin besar pula rata - rata bilangan Nusselt. Pemasangan sisipan pada tiga geometri dengan variasi sudut $(\alpha)$, yaitu $\alpha=0^{\circ}, \alpha=45^{\circ}$, dan $\alpha=90^{\circ}$, memiliki nilai rata rata bilangan Nusselt yang lebih besar dari tube tanpa sisipan dan tube dengan sisipan tanpa galur. Nilai rata-rata bilangan Nusselt untuk sisipan bergalur dengan sudut $\alpha=45^{\circ}$ memiliki nilai tertinggi, kemudian berurutan dari nilai 
rata-rata bilangan Nusselt dari yang tertinggi adalah $\alpha=90^{\circ}, \alpha=0^{\circ}$, sisipan tanpa galur, kemudian plain tube. Hal ini sesuai dengan teori bahwa fungsi sisipan yaitu menciptakan swirling motion yang memicu vortex berakibat pada penigktan pencampuran fluida sehingga meningkatkan performa perpindahan panas.

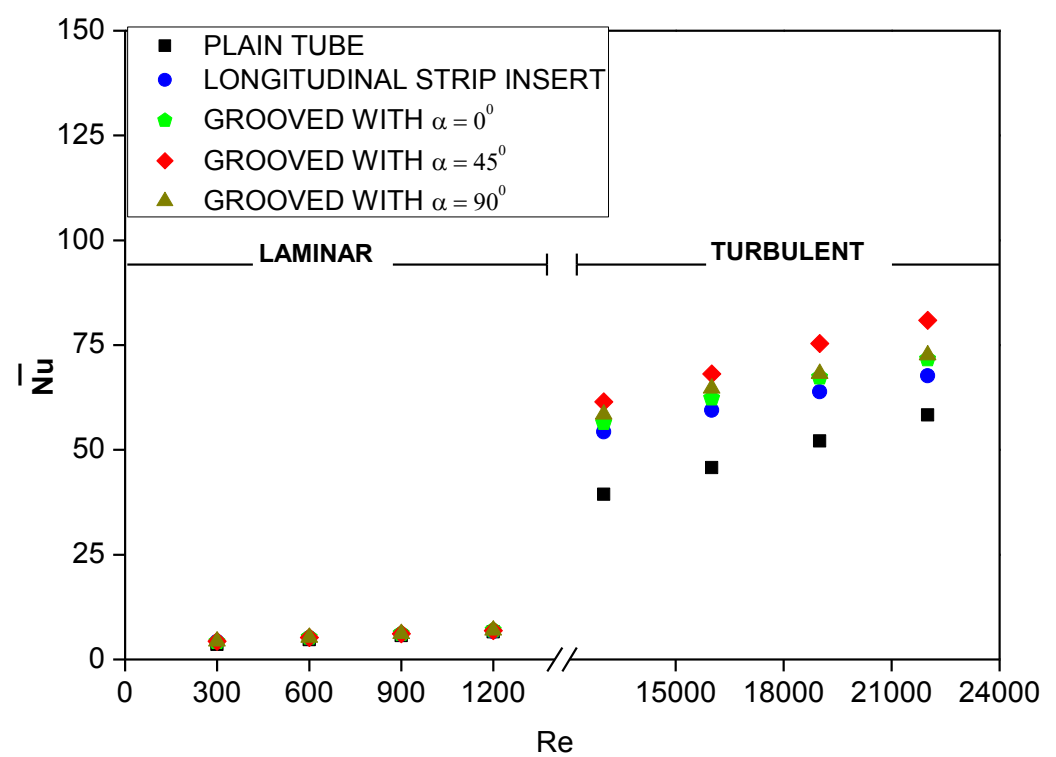

Gambar 6. Perbandingan antara bilangan Nusselt rata-rata untuk plain tube dan tube berbagai sisipan plat bergalur

Gambar 7 menunjukkan grafik perbandingan friction factor antara plain tube dan tube dengan berbagai variasi sisipan. Grafik ini berisi tentang pengaruh variasi sisipan terhadap friction factor. Sumbu x menunjukkan bilangan Reynolds sedangkan sumbu y menunjukkan friction factornya. Simbol kotak hitam menunjukkan tube tanpa sisipan, bentuk lingkaran biru menunjukkan tube yang dipasang sisipan tanpa galur, bentuk segilima hijau menunjukkan tube yang dipasang sisipan dengan galur $\alpha=0^{0}$, bentuk diamond merah menunjukkan tube yang dipasang sisipan dengan galur $\alpha=45^{\circ}$, dan bentuk segitiga coklat menunjukkan tube yang dipasang sisipan dengan galur $\alpha=90^{\circ}$. Dari grafik ditunjukkan bahwa kecenderungan friction factor menurun terhadap bilangan Reynolds. Semakin besar bilangan Reynolds, maka semakin kecil friction factor yang dihasilkan. Pemasangan sisipan pada tiga geometri dengan variasi sudut $(\alpha)$, yaitu $\alpha=0^{\circ}, \alpha=45^{\circ}$, dan $\alpha=90^{\circ}$, memiliki nilai friction factor yang lebih besar dari tube tanpa sisipan dan tube dengan sisipan tanpa galur.

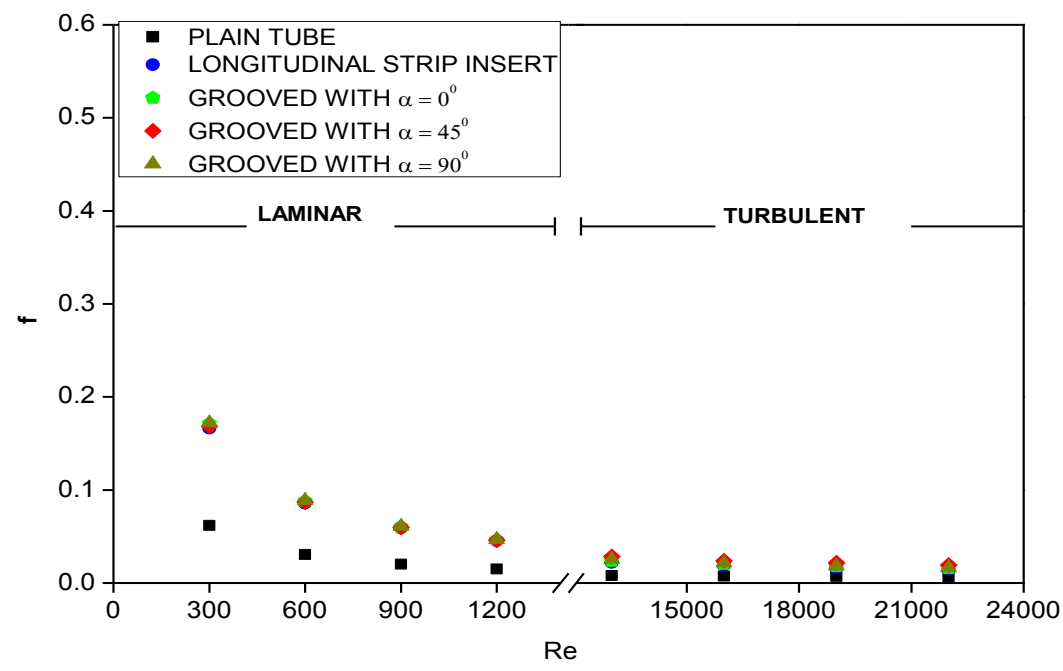

Gambar 7. Perbandingan antara bilangan Nusselt rata-rata untuk plain tube dan tube berbagai sisipan plat bergalur

\section{KESIMPULAN}

Penelitian performa sisipan plat bergalur di dalam sebuah pipa telah dilakukan. Dari hasil dan analisa dapat disimpulkan bahwa:

1. Tube sisipan bergalur dengan $\alpha=450$ memiliki nilai rata-rata bilangan Nusselt yang paling besar. Berdasarkan peningkatan nilai rata-rata bilangan Nusselt pada aliaran laminar bilangan Reynolds 300-1.200, nilai rata-rata 
bilangan Nusselt dan friction factor untuk penambahan sisipan dengan sudut $\alpha=0^{\circ}$ berturut-turut berkisar antara 5,63-17,09\% dan 176,68-206,27\%, untuk sisipan tanpa galur peningkatannya 1,29-19,25\% dan 168,8-200,52\%, untuk sisipan dengan sudut $\alpha=90^{\circ}$ peningkatannya 5,44-19,67\% dan $178,25-210,5 \%$, untuk sisipan dengan sudut $\alpha$ $=45^{\circ}$ peningkatannya $4,46-20,34 \%$ dan $172,19-204,36 \%$.

2. Berdasarkan peningkatan nilai rata-rata bilangan Nusseltnya pada aliaran turbulen bilangan Reynold 13.00022.000, nilai rata-rata bilangan Nusselt dan friction factornya untuk penambahan sisipan tanpa galur berturut-turut berkisar antara 16,04-37,8\% dan 113,43-180,25\%, untuk sisipan dengan sudut $\alpha=0^{\circ}$ peningkatannya 22,78 $43,45 \%$ dan $134,74-204,71 \%$, untuk sisipan dengan sudut $\alpha=90^{\circ}$ peningkatannya $24,52-.48,44 \%$ dan 142,19 $224,97 \%$, untuk sisipan dengan sudut $\alpha=45^{\circ}$ peningkatannya $38,67-56,1 \%$ dan $183,5-262,29 \%$.

\section{REFERENSI}

[1] Versteeg, H. K. and Malalasakera, W., 1995, “An Introduction to Computational Fluid Dynamic," Longman Scientific \& Technical, England, 11-25.

[2] Chiu, Y. W. and Jang, J. Y., 2009, "3D Numerical and Experimental Analysis for Thermal-hydraulic Characteristics of Air Flow inside a Circular Tube with Different Tube Inserts", Applied Thermal Engineering 29: 250-258.

[3] M.M.K. Bhuiya, M.S.U. Chowdhury, M. Shahabuddin, M.Saha and L.A.Memon, 2013, "Thermal characteristics in a heat exchanger tube fitted with triple twisted tape inserts", International Communications in Heat and Mass Transfer, 48: 124-132.

[4] M.M.K. Bhuiya, A.S.M.Sayem, M.Islam, M.S.U. Chowdhury and M.Shahabuddin, 2014, "Performance assessment in a heat exchanger tube fitted with double counter twisted tape inserts", International Communications in Heat and Mass Transfer, 40:25-33.

[5] W.H. Azmi, K.V. Sharma, P.K. Sarma, Rizalman Mamat, Shahrani Anuar and L. Syam Sundar, 2014, "Numerical validation of experimental heat transfer coefficient with $\mathrm{SiO} 2$ nanofluid flowing in a tube with twisted tape inserts", Applied Thermal Engineering, 73: 296-306.

[6] Changzhong Man, Jinyu Yao and Chong Wang, 2016, "The experimental study on the heat transfer and friction factor characteristics in tube with a new kind of twisted tape insert", International Communications in Heat and Mass Transfer, 75: 124-129.

\section{UCAPAN TERIMA KASIH}

Penulis mengucapkan terimakasih kepada Jurusan Teknik Mesin Fakultas Teknik Universitas Diponegoro atas dukungan pendanaan yang diberikan pada penelitian ini. 